La figura del intelectual en la Argentina del último siglo

Baal Delupi

Question/Cuestión, Nro.70, Vol.3, diciembre 2021

ISSN: 1669-6581

URL de la Revista: https://perio.unlp.edu.ar/ojs/index.php/question/

IICom -FPyCS -UNLP

DOI: https//doi.org/10.24215/16696581e626

\title{
La figura del intelectual en la Argentina del último siglo
}

\section{The figure of the intellectual in Argentina of the last century}

Baal Delupi

Centro de Estudios Avanzados-Universidad Nacional de Córdoba

Argentina

baal.delupi@mi.unc.edu.ar https://orcid.org/0000-0001-7697-3325

\section{Resumen}

El presente ensayo tiene por objetivo indagar sobre las manifestaciones intelectuales más resonantes de la Argentina del último siglo. Para ello nos proponemos, en una primera instancia, recuperar las conceptualizaciones tradicionales del intelectual, entendiendo que no se harán todas las distinciones clásicas en términos generales, sino más bien se buscará explicitar aquellas cuestiones relevantes que operan como punto de partida para pensar su dimensión política. En segundo término, trazamos un recorrido diacrónico para mostrar algunas de las publicaciones intelectuales más significativas del siglo XX y principios del XXI en Argentina: Revista Sur, Contorno, Pasado y Presente, Punto de Vista, Controversia, El Ojo 
Mocho, Grupo Esmeralda, El Club Socialista y Carta Abierta. Este recorrido permitirá ver la manera en que se fueron configurando, en distintas producciones discursivas, diferentes sujetos intelectuales que responden a periodos socio-históricos divergentes.

Palabras clave: Intelectuales; política; historia; discursos.

\section{Abstract}

This essay aims to investigate the most resonant intellectual manifestations of Argentina in the last century. For this purpose we propose, in the first instance, to recover the traditional conceptualizations of the intellectual, understanding that not all classical distinctions will be made in general terms, but rather seek to make explicit those relevant issues that operate as a starting point for thinking about their political dimension. Secondly, we trace a diachronic journey to show some of the most significant intellectual publications of the 20th and early 21st centuries in Argentina: Revista Sur, Contorno, Pasado y Presente, Punto de Vista, Controversia, El Ojo Mocho, Emerald Group, The Socialist Club and Open Letter. This tour will allow to see the way in which different intellectual subjects were configured, in different discursive productions, responding to divergent socio-historical periods.

Keywords: Intellectuals; politics; history; discourses.

\section{Introducción}

A lo largo de la historia, la figura del intelectual ha suscitado innumerables reflexiones: ¿Qué es un intelectual? ¿Cuál es su propósito? ¿Qué debe aportar a la sociedad? Las respuestas han sido muchas pero pocas han logrado conformar o responder acabadamente la cuestión de fondo. Será quizás porque es difícil precisar esa "rara especie" que se intenta definir, puesto que lo que se elabora generalmente, como dice Bauman (1997) son "autodefiniciones". En este trabajo nos interesa la figura política intelectual, nos referimos a aquellos sujetos que han intervenido en procesos socio-políticos particulares y que pueden ser 
concebidos como un emergente histórico-cultural que se construye de manera diferente según el estado de discurso (Angenot, 2010) en el que se enuncie.

Autores como Sigal (1991), Sarlo (1994), Casullo (2007), González (2012), Altamirano (2011; 2013), Elizalde (2013), Pulleiro (2017), entre otros, han trabajado la figura política del intelectual:

¿Quién llama al intelectual? Nadie. ¿En dónde está inscripta, en cada circunstancia concreta, su pretendida "Misión"? En ninguna parte [...] Esa ausencia le confiere al intelectual la idea de su misión. ¿Quién se la otorga? Una genealogía en la historia de las ideas modernas que creó en la intensidad de la historia intelectual, en la toma de conciencia como tarea intelectual crítica, la condición de la propia modernidad en tanto infinita respuesta insatisfecha, ya no emitida sólo desde los gabinetes y laboratorios de una elite, sino en y hacia los mundos de la política, hacia el conflicto expuesto, hacia el plexo de la polis (Casullo, 2007, p. 314).

No podemos pensar dicha noción de la misma manera hoy que hace 50 años. Su figura política está vinculada y condicionada por los acontecimientos que se desenvuelven mientras piensa y escribe, va configurando una ética determinada en tanto palabra pública que interviene en los diversos sucesos que atraviesan la sociedad.

Por tanto, la producción intelectual está enmarcada en un espacio de conflicto, dado que sus discursos ponen en juego prácticas y significaciones que penetran en el campo hegemónico a partir de formaciones discursivas determinadas (Pêcheux, 2016). Es decir, los discursos de los intelectuales no solo no están al margen de los procesos socio-históricos y de la puja por la hegemonía, sino que se sitúan en ese juego de tensiones. Además, su opinión suele estar legitimada por una parte de la comunidad, pero, ¿es esa comunidad representativa? ¿Son los intelectuales quienes pueden realizar cambios sustantivos? Casullo (2007) postula que "la historia del intelectual es la biografía de un pensamiento inscripto junto a la política y a la cultura" (p. 312). El intelectual, para este autor, tiene la misión de sembrar la 
crítica y los espacios políticos e ideológicos, de revisar su lugar en la esfera pública y de reflexionar acerca de la relación entre la tarea intelectual, la situación socio-cultural y los poderes políticos.

Sin dudas, el intelectual puede erigirse como una figura política particular. Solo basta ver los efectos de sentido en relación a la obra de Marx, Durkheim, Weber, Gramsci, etc. ¿Cómo hubiera sido posible el comunismo sin un pensamiento intelectual? ¿Y el anarquismo? ¿Y el capitalismo? Toda acción política concreta ha estado emparentada con una teoría, con intelectuales que pensaron, escribieron y reflexionaron sobre su tiempo histórico. En ese sentido, se puede afirmar que las grandes revoluciones se produjeron a partir de una larga 'conversación', como producto de la reflexión intelectual. Siguiendo esta línea, para poder modificar determinado contexto es necesario contar con intelectuales que reflexionen críticamente sobre su tiempo, construyendo un poder simbólico que anticipe/denuncie/advierta aquellos dispositivos de pensamiento para alojar otros sentires y pareceres que modifiquen el orden existente. En este sentido, Horacio Gónzalez, figura principal del grupo Carta Abierta (grupo en el que me detendré más adelante) dice que:

Estoy de acuerdo en intervenir en los asuntos públicos con un sentido de justicia, e incluso de escribir sobre la misma condición intelectual, como lo hizo Gramsci. El "caso Dreyfus" es uno de los tantos episodios que escinden la opinión pública nacional. Este tipo de escisiones establecen la fisura intelectual por excelencia $(2012$, p. 1).

Por su parte, Terán (2008) plantea que el vínculo del intelectual con la política y las organizaciones suele ser tensa, ya que es la figura del intelectual la que toma un lugar de debate público en tanto espacio de legitimación. El intelectual público no puede ser considerado un experto, más bien debe entenderse como un "ciudadano que busca animar la discusión de su comunidad" (Altamirano, 2013, p. 11). Su figura, entonces, debe ser pensada en la discusión democrática de su pueblo, es justamente en medio de la 'cosa pública' que aparece para decir, denunciar, anticipar e impulsar propuestas determinadas. 
En síntesis, la figura política del intelectual, que es la que interesa en este trabajo, ha sido tema de debate de muchos intelectuales y militantes a lo largo y ancho del planeta. Particularmente, como ya dijimos, nos interrogamos por un sujeto intelectual vinculado a los procesos socio-políticos de la comunidad donde se desenvuelve.

Siguiendo la tradición sobre el estudio de la historia de las ideas, particularmente recuperando los postulados de Carlos Altamirano (2013), nos proponemos ver el modo en que se construyeron distintos sujetos intelectuales en momentos singulares, con la hipótesis de que esas figuras irrumpieron en la escena pública para proporcionarle a la sociedad una conciencia inquieta de sí misma, cuestionando lo instituido y proponiendo vías emancipatorias.

A continuación, recuperamos algunas nociones que permiten conceptualizar qué es el intelectual y de qué manera se construye en distintos periodos históricos.

\section{Aproximaciones a una noción compleja}

Resultan interesantes las ideas de los filósofos griegos en el pensamiento occidental, desde las enseñanzas de Sócrates, pasando por el 'político' de Platón, hasta los escritos de Aristóteles. Si bien ellos han contribuido a pensar el rol del intelectual en la sociedad a lo largo de la historia, autores contemporáneos como Winock (2010), Altamirano (2013), González (2012), Grüner (2012) y Pulleiro (2013) coinciden en que la cuestión se plantea de manera crucial a partir del caso Dreyfus. La figura del intelectual en el terreno de lo público es una discusión de larga data: autores como Gramsci (2012 [1984]), Sartre (2012 [1948]) Walzer (1993), Sarlo (1994), Said (1996), Bourdieu (1999), Casullo (2007), Charle (2009), entre tantos otros, han ofrecido herramientas teóricas para pensar el asunto.

Altamirano (2013), por ejemplo, ofrece una definición amplia del intelectual, dice que es quien puede "proporcionar a la sociedad 'una conciencia inquieta' de sí misma, una conciencia que la arranque de su inmediatez y despierte la reflexión" (p. 46). Para el autor, la democracia suele ser el ambiente propicio para la reflexión política del intelectual, ya que sus decires no deben circunscribirse a una disciplina o comunicación específica. 
A nuestro juicio, hay algunos trabajos que pueden considerarse fundantes sobre la problemática intelectual. En primer lugar, nos referimos a "Los nuevos clercs", de Julien Benda, que rescata Altamirano (2013): el intelectual se construye como una figura que debe proteger los valores de la civilización. En segundo término, se halla el intelectual comprometido sartriano que deviene de lo que se conoce como "la tradición normativa". Sartre sostiene que los intelectuales tienen una gran responsabilidad y deben guardar su autonomía en relación a los poderes y aparatos políticos (Sartre, 1962). En tercer lugar, aparece el intelectual orgánico y tradicional propuesto por Antonio Gramsci: toda clase que quiera conquistar la hegemonía de una sociedad debe contar con nuevos intelectuales que edifiquen trincheras en las diferentes zonas de la esfera pública (Gramsci, 2012 [1948]). De este modo, según Pulleiro (2013) se amplía la noción de intelectual y se relaciona esa categoría con tareas organizativas. Como cuarta caracterización, surgen los aportes de Walzer (1993), quien entiende que la función del intelectual es estar dentro de la comunidad como un "articulador de la queja común". Por último, se sitúa el intelectual crítico de Said (1996): lo que define a un intelectual es la crítica que hace de su tiempo histórico. Propone la idea del intelectual como 'francotirador', una persona que plantea cuestiones incómodas para los gobernantes, desafiando los poderes ideológicos y religiosos.

Otro autor que resulta relevante a la hora de analizar qué es un intelectual es Pierre Bourdieu. En Intelectuales, política y poder (1999) el autor piensa en los intelectuales de la sociedad moderna y postula que, así como la nueva demagogia política utiliza los "sondeos" para legitimar políticas neoliberales, tiene que haber intelectuales que se organicen en medios de expresiones independientes y libren la lucha colectiva a favor de la ofensiva progresista:

Los intelectuales no tienen que justificar su existencia a los ojos de sus compañeros [...] tienen que ser lo que son, que producir y que imponer su visión del mundo social que no es necesariamente mejor ni peor que las otras-, y que dar a sus ideas toda la fuerza de la cual son capaces. No son los portavoces de lo universal, menos todavía una "clase universal" (Bourdieu, 1999, p. 172). 
Otro de los libros sobre la historia intelectual europea es el de Hugo Biagini (1995). En esta obra el autor reflexiona acerca del rol de importantes intelectuales y políticos españoles en los comienzos de la inmigración masiva; en su mayoría, emigraron hacia Argentina y emprendieron un proceso importante en ese país. Biagini dice que esos intelectuales fueron claves en la modernización y renovación democrática de la región del Plata. Sus investigaciones son relevantes para reflexionar la construcción de identidades intelectualesnacionales a partir de la llegada de los españoles al Río de la Plata, con su impronta y su cultura, con su conocimiento sobre un deber ser intelectual europeo distinto al que estaba en nuestro país.

Es preciso destacar la importancia de dos autores: Christophe Charle (2000) y Michel Winock (2010). Ambos han abordado el tema de los intelectuales europeos en distintos siglos. Charle procura mostrar la importancia de dichos sujetos en el siglo XIX, dice que ese momento es clave dado que distintos pensadores comienzan a asumir, dentro del campo cultural y político, el papel de revolucionarios y vigilantes. Winock, por su parte, marcará la relevancia de los intelectuales franceses del siglo XX. Postula que Francia, en ese período, es determinante para pensar la historia intelectual desde el caso Dreyfus (1898), pasando por los años de entreguerras de André Gide y finalizando con la época sartriana. Al autor no le interesa recapitular una historia de las ideas, sino hablar directamente de los enfrentamientos políticos más importantes, conflictos donde la intervención intelectual es clave. Si bien ambos trabajan itinerarios de intelectuales europeos, sus análisis son relevantes para la comprensión de las tipologías clásicas, sobre todo en el siglo XX, asunto que nos interesa dado que los intelectuales argentinos se inspiran en esas tradiciones.

En Latinoamérica, el estudio de la historia intelectual también data de muchas décadas. Podríamos comenzar con autores de diversas nacionalidades que han pensado este asunto: un ejemplo de ello es el cubano Martí, quien a fines de 1800 ya daba muestras del rol intelectual en los procesos sociopolíticos. Mariátegui (importante para toda la historia intelectual latinoamericana), desde Perú dejaba clara su posición en 1927: "en el conflicto entre explotadores y explotados, en la lucha entre socialismo y capitalismo, la neutralidad intelectual es imposible" (1979, p. 16-17). 
Siguiendo con Cuba, un libro importante es Palabras a los intelectuales (2011) del ex presidente Fidel Castro, producto de una reunión con artistas y escritores cubanos el 30 de junio de 1961 (a tres años de la revolución), les habla a los intelectuales acerca del compromiso que tienen que tener con el proceso histórico-político que se estaba llevando a cabo en la isla: "dentro de la revolución todo; contra la revolución, nada" (p. 11). Es en medio del proceso revolucionario que Castro señala la importancia del acompañamiento de los intelectuales, de su misión en el tiempo histórico. Volvemos a los planteos de Gramsci en tanto que el intelectual aparece como vehículo para disputar sentido en un estado de discurso, su presencia también construye hegemonía y su figura política es necesaria para llevar adelante determinadas reformas. El libro de Castro, entonces, fue significativo para la generación de intelectuales y militantes setentistas.

En Argentina, los trabajos de Sigal (1991), Sarlo (1994), Patiño (1998; 2004), Burgos (2004), Casullo (2007), Gónzalez (2008), Altamirano (2010; 2013), Elizalde (2013), Pulleiro (2013; 2017), Acha (2014), Tatián, (2015), Prislei (2015), Ricca (2016), Petra (2016), Waiman (2016), Dal Maso (2016), Cortés (2017), Tarcus (2020) entre otros, constituyen un material enriquecedor dado que se interrogan por la figura política del intelectual desde principios de siglo XX hasta nuestros días. ¿Qué es un intelectual? ¿De qué modo se cristaliza su rol político en el espacio público? ¿Qué vínculo ha tenido con los procesos electorales y los movimientos sociales? ¿Cómo se modificó su figura a través del tiempo? Son algunas de las preguntas que se hacen en sus trabajos. Quizás el más completo de todos en términos cronológicos sea el de Altamirano, quien desarrolla cuidadosamente las transiciones e intersecciones intelectuales en las últimas décadas del siglo XX.

Sigal, Patiño, Prislei, Petra y Tarcus caracterizan a los intelectuales de los años '50, ' 60 y ' 70 , sus trabajos permiten comprender las distintas miradas sobre el intelectual en esas tres décadas, atendiendo al contexto político, social, cultural y económico. También explican las pasiones de aquellos pensadores por la militancia revolucionaria y la literatura. Nos interesa recuperar sus ideas sobre las trayectorias intelectuales en la Argentina del siglo XX y principios del XXI, sobre todo a partir de revistas como Sur, Contorno, Sur y Pasado y Presente.

Por su parte, Pulleiro hace un recorrido significativo por las tradiciones intelectuales del último siglo, estableciendo lazos pasado-presente que se anudan en los momentos de crisis: 
intelectuales que en determinadas situaciones álgidas del país vuelven a aparecer en la escena pública. Analiza específicamente la participación de grupos intelectuales en la coyuntura de 2001, momento que resulta determinante para la creación posterior del grupo Carta Abierta en el año 2008.

Los escritos de Casullo, González y Tatián ofrecen herramientas para identificar, con cierto detalle, aquella zona fronteriza que se establece entre el intelectual y la política, enunciando determinado 'deber ser' que tiene el intelectual en los procesos socio-políticos. El análisis de los autores se circunscribe a la escena local, con las trayectorias y discursos más emblemáticos, analizando el rol de la izquierda, el peronismo, la Universidad, el exilio y las distintas generaciones intelectuales.

\section{II.5. Intelectuales argentinos: entre críticos, comprometidos, revolucionarios, exiliados y partidarios}

Sin pretender hacer un recorrido exhaustivo en los diversos grupos intelectuales y figuras públicas que se fueron sucediendo en la Argentina, nuestro interés es trazar un recorrido sobre aquellos procesos donde el intelectual se manifestó como un sujeto político particular, específicamente en el siglo XX y principios del XXI. Por este motivo no hablaremos de los intelectuales en general, sino de algunas figuras que se fueron transformando en el tiempo y que explican, en algún aspecto o carácter, la manera en que se ha construido el campo político del intelectual en la Argentina.

Como ya dijimos, siguiendo la tradición del estudio sobre la historia de las ideas, particularmente recuperando los postulados de Carlos Altamirano (2013), nos proponemos dar cuenta la manera en que se construyeron figuras intelectuales en distintos momentos históricos.

Es importante entender las particularidades que tiene analizar la figura política del intelectual en Argentina, puesto que cada país tiene una historia singular. En este sentido, Navarro (2021) dice que no hay que caer en categorías universales ni transpolaciones innecesarias 
Como bien señala el documento del Prince Claus Fund que nos convoca, "en varios aspectos el papel de los intelectuales difiere de país en país", y también los "constreñimientos materiales, culturales y políticos" que ellos experimentan "difieren de situación en situación". Es preciso tener en cuenta esas diferencias si no se quiere correr el riesgo de incurrir en extrapolaciones ilícitas, generalizaciones infundadas y etnocentrismos. En efecto, como añade el documento: "Hay necesidad de entender el papel de los intelectuales en esos contextos y discutir los dilemas clave" (p. 67).

Creemos junto con Altamirano (2011), Waiman (2016), Pulleiro (2017) y Tarcus (2020) que los grupos que desarrollaremos (de manera breve) a continuación tuvieron una importante relevancia en la historia intelectual de Argentina. Con esto no queremos afirmar que son los únicos, puesto que se podría indagar sobre otros, pero sí coincidimos que son espacios resonantes que permiten entender la proliferación de publicaciones y colectivos en la esfera pública en el último siglo. Además, es posible advertir el modo en que estos grupos irrumpieron en la escena pública para proporcionarle a la sociedad una conciencia inquieta de sí misma, y no es casualidad que hayan surgido en ese estado de discurso.

También es importante precisar que por una cuestión de extensión y propuesta del presente ensayo, no vamos a ser exhaustivos con cada grupo, más bien se trata de mostrar, como dijimos en varias oportunidades, la importancia que tiene mirar de manera diacrónica las distintas manifestaciones intelectuales en Argentina.

En 1931 aparece la revista literaria Sur fundada por Victoria Ocampo e integrada por un consejo extranjero de intelectuales como Ernest Ansermet, Leo Ferrero, Pedro Henríquez Ureña, José Ortega y Gasset. El comité de redacción estaba compuesto por Jorge Luis Borges, Oliverio Girondo, Eduardo Mallea, Guillermo de Torre, entre otros.

En esa revista comienza una suerte de profesionalización del intelectual, su rol se vuelve más delimitado. La publicación apuntó, entre otras cosas, a la traducción de libros europeos para pensar desde el "sur". Es una referencia destacable dado que también se 
promueve la reflexión sobre el intelectual como un 'incomodador' que opera en espacios específicos de formación académica/universitaria. La revista fue discutida por sus colegas contemporáneos y por publicaciones posteriores dado que construyó una figura de intelectual de alta cultura que analizaba diversas producciones discursivas (Pasternac, 2002).

Respecto a la figura política, es importante destacar el rol y los escritos de algunos miembros de su comité editorial, sobre todo de Borges, quien reflexionó siempre sobre la realidad argentina. Con más o menos metáfora, atendía los procesos socio-políticos del país y sus cuestionamientos al peronismo son conocidos, refutados y estudiados en las ciencias sociales y humanas. Así, el intelectual aparece vinculado al propuesto por Julien Benda, en tanto representa un modelo que busca proteger los valores de la civilización.

Veintidós años más tarde aparece una revista como Contorno, en un contexto disímil que ya conocía la transformación social del peronismo y que transitó la proscripción de ese movimiento y el gobierno de Frondizi. La fundación de la publicación estuvo a cargo de Ismael Viñas, agregándose luego su hermano David. Fue una publicación emblemática de la izquierda intelectual argentina, un grupo de jóvenes que pondrían en tensión la relación entre literatura y sociedad. La revista tuvo diez números, dos cuadernos y cerró en 1959. Nos interesa recuperar la caracterización que hace Serveto (2016) del colectivo:

Intelectuales sin partido o frágilmente encuadrados en los partidos comunistas y socialistas, trotskistas y ex-trotskistas, el grupo alrededor de la revista Contorno puede ser considerado como uno de los puntos de partida, en tanto allí se encuentran los 'síntomas de la busca de una identidad intelectual diferente (p. 271).

Se puede decir que en Contorno operó una lógica reflexiva y combativa antiperonista que expresó la función contestataria del intelectual. Se vincula esta figura política con la de Sartre en tanto compromiso con su tiempo histórico. 
Casi diez años más tarde, en 1963, aparece Pasado y Presente, revista que llevará el modelo de intelectual comprometido a su máxima expresión, creando una tipología singular que no se volverá a repetir hasta nuestros días: el intelectual revolucionario. El colectivo cordobés entendía, desde Gramsci, que la forma de transformar la sociedad era la revolución y que los intelectuales eran el vehículo esencial para ese cambio (Burgos, 2004; Altamirano 2011). José María Aricó, Héctor Schmucler, Oscar del Barco, Juan Carlos Portantiero fueron las principales figuras de esta publicación.

La revista es atravesada por hechos mundiales significativos: la Revolución cubana, la de Vietnam, la sandinista y el gobierno de Salvador Allende. En Córdoba y Argentina se suceden acontecimientos dictatoriales y revolucionarios: por un lado, la dictadura autodenominada Revolución Argentina y, por otro, el Cordobazo. Escriben hasta el año 1973, muchos de los intelectuales de dicha publicación se exilian a raíz del golpe militar de 1976.

Siguiendo con el orden cronológico, la figura política del intelectual en la última dictadura argentina (1976-1983) es muy compleja de analizar, podríamos decir que están "los que se fueron" y los que "se quedaron". En el primer grupo se encuentran los intelectuales que fundaron, en México, la revista Controversia, una publicación que analizaba la coyuntura latinoamericana y se interrogaba por los errores del pasado. El repertorio tópico se centraba en el exilio, el marxismo, el peronismo, los derechos humanos, la lucha armada y la dictadura argentina. Se publicaron catorce números y dos cuadernos entre los años 1979 y 1981; colaboraron intelectuales de Contorno, como Noé Jitrik y David Viñas, como así también de Pasado y Presente: Aricó, del Barco, Schmucler, Portantiero y Rozitchner; además, participaron intelectuales que son importantes en la historia argentina, algunos de ellos son Nicolás Casullo, Osvaldo Bayer, Julio Cortázar, Néstor García Canclini, Jorge Abelardo Ramos, entre otros.

Del lado de los que se quedaron, aparece como emblema la revista Punto de Vista, que surge en 1978, creada por Beatriz Sarlo, Carlos Altamirano, Ricardo Piglia y Elías Semán. Esta publicación llegó hasta su número 90 en el año 2008. Era muy difícil escribir en esa época (Altamirano, 2013), ya que se perseguía a militantes y artistas quemando libros, torturando y desapareciendo a aquellos que "desafiaran" el orden establecido. Sin embargo, no todos los 
artistas e intelectuales se exiliaron, un número importante de ellos resistió en territorio nacional intentando 'decir' en un momento trágico para el país.

Lo relevante de estas publicaciones es que construyen una figura política del intelectual un tanto singular, ya sea los que se marcharon como los que atravesaron la dictadura militar en Argentina. Por un lado, los que se fueron a México y otros sitios, con el dolor de no poder volver y estar lejos de los afectos; mientras que, por el otro, estaban aquellos que se quedaron con miedo de vivir y con la incertidumbre permanente sobre las represalias que podían tener a raíz de la reflexión crítica.

Luego de ese periodo oscuro de la historia argentina se produce el retorno de la democracia, en 1983. Como dijimos anteriormente, la dictadura cívico-militar marcó un antes y un después respecto del rol del intelectual argentino. El ímpetu revolucionario sufrió un duro traspié con el exilio de muchos intelectuales, su rol político ya no será el revolucionario produciéndose un acercamiento al alfonsinismo: El Grupo Esmeralda fue clave en ese vínculo, muchos intelectuales advirtieron que su rol ya no era buscar la forma de hacer la revolución armada, más bien, entendieron al Estado como un espacio de disputa que permite, en el mejor de los casos, vivir mejor bajo un sistema democrático.

Aparece en escena una figura inédita en Argentina, la del intelectual ligado de manera explícita y orgánica al gobierno, en este caso el de Alfonsín. Se armó un grupo de trabajo de "análisis del discurso" (Campos Ríos, 2013). Algunos de los intelectuales más destacados, bajo la coordinación de Margarita Graziano, fueron Gabriel Kessler, Claudia Hilb y Daniel Lutzky, Sergio Bufano, Damián Tabarosky, Hugo Raport, Marcelo Cosin, Juan Carlos Portantiero y Emilio de Ipola. La figura política del intelectual se expresa de manera singular con una organización única, personas que quizás en otro momento no se hubieran juntado se nuclearon para acompañar al presidente de ese momento.

Por otra parte, el Club Socialista (1984-2008) fue un espacio de relevancia para los intelectuales argentinos de la generación del exilio: "procesaron colectivamente la ruptura con los ideales revolucionarios, e incorporaron una visión pluralista (y cada vez más formalista) de la democracia. Fue también un lugar con proyección política" (Svampa, 2012, p. 1). Se 
construye un sujeto intelectual desligado de la idea revolucionaria, en sintonía con el Grupo Esmeralda, entendiendo que el horizonte debía ser el sostenimiento de la democracia.

En los años '90, como plantea Sarlo (1994), hay un desplazamiento hacia un modelo tecnocrático y mediático. Fue en programas de televisión como Hora Clave que se construyeron personajes como Mario Grondona y Bernardo Neustadt, que en sintonía con la época defendían el modelo neoliberal. Sin embargo, hay una publicación que fue importante en medio de ese giro, me refiero a El ojo mocho (1991-2008), fundada en el verano de 1991 en la Facultad de Ciencias Sociales de la Universidad de Buenos Aires. La revista fue clave en una época difícil de reformas neoliberales y triunfo del capitalismo. El Ojo Mocho constituyó la resistencia en esta década, sus figuras centrales fueron Horacio González (quien luego fundará Carta Abierta) y Eduardo Rinesi. Además, esa publicación se dedicó a mostrar la importancia que debían tener las ciencias sociales en la coyuntura, construyendo una figura política heterodoxa del intelectual (Pulleiro, 2017).

El Ojo Mocho operó como una suerte de contrapunto a la revista Punto de Vista. Si bien en las primeras publicaciones esto no se hizo explícito, ya se evidenciaba en el nombre elegido y en un horizonte temático común: la función del intelectual, el papel de ciertas tradiciones y la tarea de la crítica cultural.

La figura política del intelectual vuelve a cristalizarse con fuerza en la esfera pública en la crisis argentina del 2001. En ese periodo disputaron sentido grupos vinculados a la "fracción liberal-conservadora y liberal-democrática", por un lado; y los llamados "populistas" o "de izquierdas", por el otro (Pulleiro, 2017). Se expresan, en ese momento, grupos de diversas tradiciones de la historia intelectual argentina.

En ese momento, no solo la figura revolucionaria estaba descartada, sino también la que ligaba a los intelectuales con el gobierno de turno. El descreimiento hacia la clase política como un vehículo para transformar la realidad estaba representada en la insistente frase "que se vayan todos". Por tanto, el intelectual se embarcó en una difícil tarea: sin tiempo para hacer largas reflexiones tuvo que adoptar posturas en una situación que cambiaba día a día en lo que fue una suerte de estado anárquico. 
Por último, dejando atrás la crisis de 2001 y con una mejor perspectiva social y económica aparece el grupo Carta Abierta. El kirchnerismo propugna la intervención de intelectuales en la escena pública, quienes van a retomar el espíritu crítico de los '70 pero acompañando de manera partidaria al gobierno kirchnerista. En las primeras tres cartas se caracterizan por ser críticos con su tiempo, retomando ideales sartreanos y con destellos gramscianos; sin embargo, a partir de la cuarta carta aparece una transformación, el espacio liderado por Horacio Gónzalez, Ricardo Forster, José Pablo Feinmann, entre otros, defienden al gobierno kirchnerista transformándose en el brazo intelectual de ese espacio político (Elizalde, 2004). El grupo dejó de escribir en el año 2019 después del triunfo del gobierno de Alberto Fernández, luego de cuatro años de macrismo. Así, la figura política del intelectual que expresa Carta Abierta sufre distintos estadíos.

Carta Abierta ilustra también la consolidación de una nueva figura del intelectual político; ya no la del "consejero del príncipe" -que fue la figura que se difundió bajo el alfonsinismo, con el Grupo Esmeralda-, sino la del "intelectual funcionario", asociado a la política como gestión (Svampa, 2012, p. 1).

En síntesis, la figura política del intelectual en Argentina se fue transformando de manera notable en el siglo XX hasta llegar a la primera década del siglo XXI: pueden observarse desde las revistas literarias con ejes políticos, pasando por el ideal comprometido que buscaba ligar al intelectual con la coyuntura política, el revolucionario de los ' 60 y ' 70 , los exiliados y los que se quedaron, los de la recuperación democrática y los ideales republicanos, aquellos que participaron de la crisis de 2001 en un estado anárquico, hasta los intelectuales de Carta Abierta en la época kirchnerista. Esa mutación permite explicar los modelos políticos que emergieron en Argentina y que dialogan entre sí como cualquier discurso, no porque sean necesariamente deudores unos de otros, sino porque la semiosis es necesariamente rizomática. Críticos, comprometidos, revolucionarios, exiliados y partidarios son las figuras que se reconocen en este recorrido. 
A su vez, estas trayectorias se vinculan, como vimos, con modelos intelectuales ya desarrollados al principio de este trabajo. El comprometido, el orgánico, el francotirador, y otras nuevas formas de pensar el rol intelectual en nuestro país. Los discursos de los grupos mencionados se suman a una memoria semiótica que tiene puntos de contacto y tensión.

\section{Conclusiones}

Es relevante volver a preguntarnos una y otra vez por la figura del intelectual, sujeto clave en toda disputa social, cultural, económica y política. A lo largo de la historia, como vimos, muchas han sido las definiciones y rasgos atribuidos al trabajador de la intelligentsia que se presenta de distinta forma según el estado de discurso en el que se sitúa. No es lo mismo preguntarse por el intelectual en 1960 o 1990, que hoy en 2021, cada momento histórico demanda de distintas figuras políticas e intelectuales.

Los autores que citamos aquí, desde los europeos como Sartre o Gramsci, pasando por Fidel Castro en Cuba, hasta los argentinos como Casullo, Tatián, Cortés o Acha, trabajan de distinta manera la noción de intelectual; sin embargo, todos coinciden en lo importante que ha sido la presencia de dicho sujeto en determinados momentos históricos para cuestionar lo instituido pero también para proponer nuevos horizontes emancipatorios. Queda pendiente indagar sobre las figuras intelectuales conservadoras o de derecha que han atravesado tanto la historia argentina como la latinoamericana, un tema poco estudiado que constituye una tarea por venir.

Críticos, comprometidos, revolucionarios, exiliados y partidarios son algunas de las figuras intelectuales que, a través de sus publicaciones generaron sentidos notables, resignificando la tarea intelectual vinculada a los procesos socio-políticos. Se podrían haber escogido otros grupos intelectuales y establecer otras comparaciones, pero decidimos coincidir con autores como Altamirano (2011), Waiman (2016), Pulleiro (2017), Tarcus (2020) respecto de la importancia de dichos colectivos en la Argentina del último siglo.

Hoy asistimos a un momento de hiperconectividad, capitalismo tardío y pérdida de las identidades tradicionales, es por eso que creemos, junto con autores como Sarlo (1994) o 
Berardi (2017), que la figura clásica del intelectual no tiene la misma resonancia que hace algunas décadas. Las redes sociales modificaron la manera de comunicarnos, la inmediatez incesante obtura la posibilidad del pensamiento crítico sobre los sucesos que nos rodean. En dicho escenario, es preciso preguntarnos qué lugar ocupa hoy el intelectual, figura necesaria para poder reflexionar sobre un tiempo histórico que cada día se complejiza más y más. En este mundo aciago, el intelectual sigue teniendo cosas para decir.

\section{Referencias bibliograficas}

Acha, O. (2014). Releer Pasado y Presente: ¿por qué, desde dónde y para qué? Prismas Revista de Historia Intelectual, núm. 18, junio, 2014, pp. 239-242.

Altamirano, C. (2013). Intelectuales. Notas de investigación sobre una tribu inquieta. Buenos Aires, Argentina: Siglo XXI.

Bauman, Z. (1997). Legisladores e Intérpretes: sobre la modernidad, la posmodernidad y los intelectuales. Trad. cast. de Horacio Pons. Buenos Aires, Argentina: Universidad Nacional de Quilmes.

Burgos, R. (2004). Los Gramscianos argentinos. Cultura y política en la experiencia de Pasado y Presente. Buenos Aires, Argentina: Siglo XXI.

Biagini, H. (1995). Intelectuales y políticos españoles a comienzos de la inmigración masiva. Buenos Aires, Argentina: Centro Editor de América Latina.

Bourdieu, P. (1999). Intelectuales, política y poder. Buenos Aires, Argentina: Eudeba.

Campos Ríos, Maximiliano (2013) "Portantiero". Recuperado de https://www.pagina12.com.ar/diario/universidad/10-232336-2013-10-29.html

Casullo, N. (2007). Las cuestiones. Buenos Aires, Argentina: Fondo de Cultura Económica.

Charle, C. (2000). Los intelectuales en el siglo XIX. Madrid, España: Siglo XXI. 
Cortes, M. (2017). José Aricó. Dilemas del marxismo de América Latina. Buenos Aires, Argentina: CLACSO.

Dal Maso, J. (2016). El marxismo de Gramsci. Notas de lectura sobre los Cuadernos de la cárcel. Buenos Aires, Argentina: Ediciones IPS.

Elizalde, J. (2009). Intelectuales y política en la transición democrática: el Grupo Esmeralda [Tesis de Maestría, FLACSO. Sede Académica Argentina, Buenos Aires].

González, H. (2012). El duelo epistolar: Sarmiento contra Alberdi. Historia crítica de la literatura argentina. Amante, A. (dir.) Buenos Aires, Argentina: Emecé.

Gramsci, A. (2012 [1948]). Los intelectuales y la organización de la cultura. Buenos Aires, Argentina: Nueva Visión.

Grunner, E. (2012). Los intelectuales, la cultura y el poder. Entrevista para Revista Topía. Un sitio de sociedad, psicoanálisis y cultura. Recuperado de https://www.topia.com.ar/articulos/intelectuales-cultura-y-poder .

Mariáteguí, J. C. (1979). 7 ensayos de interpretación de la realidad peruana. Caracas, Venezuela: Ayacucho.

Navarro, D. (2021). El triunfo sobre la roca. Selección de ensayos. Ciudad de México, México: Universidad Nacional Autónoma de México Instituto de Investigaciones Filológicas.

Patiño, R. (2004). Intelectuales, literatura y política. Umbrales y catástrofes. Epoké Estudios críticos. Córdoba, pp. 15 a 28.

Pasternac, N. (2002). Las escritoras en la revista Sur: un ejercicio de recuperación de la memoria literaria. Iztapalapa. Revista de ciencias sociales y humanidades, Universidad Autónoma Metropolitana.

Pêcheux, M. (2016). Las verdades evidentes. Lingüística, semántica, filosofía. Buenos Aires, Argentina: Centro cultural de la cooperación Floreal Gorini. 
Pulleiro, A. (2013). El papel de los intelectuales en la Argentina reciente: una aproximación a la experiencia de 'Carta Abierta". Iberofórum. Revista de Ciencias Sociales de la Universidad Iberoamericana. Año VIII, No. 15.

Pulleiro, A. (2017). Liberales, populistas y heterodoxos. Estudios sobre intelectuales, cultura y política en la Argentina reciente. Buenos Aires, Argentina: Batalla de ideas.

Ricca, G. (2016). Nada por perdido: política en José María Aricó: un ensayo de lectura. Río Cuarto, Argentina: Universidad Nacional de Río Cuarto.

Said, E. (1996). Representaciones del intelectual. Buenos Aires, Argentina: Paidós.

Sarlo, B. (1994). Escenas de la vida posmoderna. Intelectuales, arte y videocultura en la Argentina. Buenos Aires, Argentina: Ariel.

Sarlo, B. (2011). La audacia y el cálculo. Buenos Aires, Argentina: Sudamericana.

Sartre, JP. (2012 [1948]). ¿Qué es la literatura? Buenos Aires, Argentina: Losada.

Servetto, A. (2016). Intelectuales y poder en la década del sesenta. Revista Estudios Digital, (4), 269-272. https://doi.org/10.31050/re.v0i4.14341

Sigal, S. (1991). Intelectuales y poder en la década del sesenta. Buenos Aires, Argentina: Ediciones Punto Sur.

Svampa, M. (2012). Los intelectuales, la cultura y el poder. Entrevista para Revista Topía. Un sitio de sociedad, psicoanálisis y cultura. Recuperado de https://www.topia.com.ar/articulos/intelectuales-cultura-y-poder

Tatián, D. (2019). Tareas intelectuales en la encrucijada latinoamericana. Revista debate. Centro Andino de Acción Popular: Quito.

Tarcus, H. (2020). Las revistas culturales Latinoamericanas. Giro material, tramas intelectuales $y$ redes revisteriles. Temperley, Argentina: Tren en movimiento.

Terán, O. (2008). Historia de las ideas en Argentina. Buenos Aires, Argentina: Siglo XXI. 
Question/Cuestión, Vol. 3, № 70

Diciembre 2021

ISSN 1669-6581

Walzer, M. (1993). La compañía de los críticos. Intelectuales y compromiso político en el siglo $X X$. Buenos Aires, Argentina: Nueva visión.

Winock, M. (2010). El siglo de los intelectuales. Buenos Aires, Argentina: Edhasa. 